\title{
G Research Square \\ Identification of active small-molecule modulators targeting the novel immune checkpoint VISTA
}

\section{Ting-ting Li}

China Pharmaceutical University

Jing-wei Jiang

China Pharmaceutical University

Chenxin Qie

China Pharmaceticial University https://orcid.org/0000-0003-2743-2754

\section{Chun-xiao Xuan}

China Pharmaceutical University

\section{Xin-lei Hu}

China Pharmaceutical University

Wan-mei Liu

China Pharmaceutical University

\section{Wen-ting Chen}

China Pharmaceutical University

Jun Liu ( $\square$ junliu@cpu.edu.cn )

China Pharmaceutical University https://orcid.org/0000-0003-2008-0258

\section{Research article}

Keywords: VISTA; small-molecule modulator; antagonist; homology modeling; virtual screening

Posted Date: March 9th, 2020

DOI: https://doi.org/10.21203/rs.3.rs-16416/v1

License: (c) (1) This work is licensed under a Creative Commons Attribution 4.0 International License.

Read Full License

Version of Record: A version of this preprint was published at BMC Immunology on August 11th, 2021. See the published version at https://doi.org/10.1186/s12865-021-00446-4. 


\section{Abstract}

Background: Cancer immunotherapy has gained increasing popularity as a novel approach to treat cancer. A member of the B7 family, V-domain immunoglobulin suppressor of T-cell activation (VISTA) is a novel immune checkpoint that regulates a broad spectrum of immune responses. VISTA is an acidic $\mathrm{pH}-$ selective ligand for P-selectin glycoprotein ligand-1(PSGL-1). CA-170, a first-in-class small-molecule dual antagonist of VISTA/PD-L1, was collaboratively developed by Aurigene Discovery Technologies Limited and Curis, Inc. It is currently in Phase I clinical trial.

Results: In this study, we develop homology modeling for the VISTA 3D structure and subsequent virtual screening for VISTA small-molecule hit ligands. Visualization of the binding postures of docked ligands with the VISTA protein indicates that some small molecular compounds target VISTA. The ability of antagonist to disrupt immune checkpoint VISTA pathways was investigated though functional studies in vitro.

Conclusions: Affinity active molecule for VISTA was obtained through virtual screening, and the antagonist compound activity to VISTA was assayed in cellular level. We reported a small molecule with high VISTA affinity as antagonist, providing ideas for development VISTA-targeted small molecule compound in cancer immunotherapy.

\section{Background}

Immune checkpoints provide inhibitory signals to maintain self-tolerance and protect peripheral tissues from damage during immune responses[1,2]. Immune checkpoint inhibitors may release the brake on the immune system, allowing it to target cancer cells. Antibodies targeting immune checkpoint cytotoxic $T$ lymphocyte antigen-4 (CTLA-4) and programmed death protein 1 (PD-1)/programmed cell death ligand 1 (PD-L1) have been broadly applied in the clinic and have yielded promising results as immunotherapy for diseases such as late-stage metastatic melanoma and nonsmall cell lung cancer (NSCLC) [3-8].

However, the clinical application of antibody-based immunotherapy has encountered a number of problems, including a low response rate (20-30\%)[4], the inconvenience of intravenous administration, immune-related adverse events (irAEs) and high cost for patients. In recent years, scientists have been dedicated to identifying additional immune checkpoint pathways and orally available small molecules to overcome these flaws.

Among the expanding list of immune checkpoints, V-domain immunoglobulin suppressor of T-cell activation (VISTA)[9] has been indicated as an important regulator of the immune system. VISTA is a type I transmembrane protein consisting of a single $\mathrm{N}$-terminal immunoglobulin (Ig) $\mathrm{V}$ domain, an approximately 30-amino acid (aa) stalk, a transmembrane domain, and a 95-aa cytoplasmic tail. The closest homolog within the B7 family is PD-L1, which shares a modest $23 \%$ sequence identity with VISTA. VISTA regulates a broad spectrum of immune responses[10-16], and is highly expressed on myeloid cells and tumor-infiltrating lymphocytes (i.e., macrophages and myeloid-derived suppressor cells (MDSCs)). It 
is also expressed on naïve $\mathrm{CD} 4^{+}$and $\mathrm{CD} 8^{+} \mathrm{T}$ cells, where it negatively regulates T-cell responses. VISTA is reported as an acidic pH-selective ligand for PSGL-1 recnetly[17]. Studies of multiple tumor models, autoimmune disease models and clinical samples have demonstrated a pivotal regulatory role of VISTA on the immune system and its potential as a therapeutic or combinational drug target.

The feasibility of targeting VISTA for cancer treatment is manifested by findings indicating high VISTA expression on tumor cells in approximately $20 \%$ of NSCLC specimens[18]. Clinical studies have shown that VISTA expression is upregulated in gastric and oral squamous carcinoma[19,20]; it is also increased after ipilimumab therapy in patients with prostate cancer[21-23]. Furthermore, previous studies have shown that VISTA is highly expressed in immune cell subsets from human pancreatic cancer patients[24].

The VISTA antibody drug trial was terminated in the clinical phase[25]. Noelle et al. first identified a peptide of VISTA antagonists through phage display. The peptide antagonist enhanced T cell proliferation in vitro and significantly enhanced antitumor immunity[26]. A small-molecule inhibitor of VISTA/PD-L1 (CA-170, the compound structure has not yet been disclosed)-collaboratively developed by Aurigene Discovery Technologies Limited and Curis, Inc-can restore the IFN- $\gamma$ production inhibited by soluble VISTA upon induction of human peripheral blood mononuclear cells (PBMCs) with anti-CD3 and anti-CD28 antibodies[27,28]. Currently, compound CA-170 is undergoing Phase I clinical trial for advanced tumors and lymphoma (NCT02812875)[29]. CA-170 exhibits potent activity when tested in assays to rescue lymphocyte proliferation and effector functions inhibited by PD-L1, PD-L2, or VISTA/PD-1H proteins. In a panel of functional assays, CA-170 showed selectivity against other immune checkpoint pathways including CTLA4, LAG3, and BTLA. These non-clinical data provided a strong rationale for the clinical development of CA-170[30-32].

In addition to being a promising target for cancer treatment, VISTA is also a key regulator of several types of autoimmune inflammatory diseases due to its multifaceted role in modulating both innate and adaptive immune responses. Antagonistic or agonistic agents can conceivably modulate VISTA and its interacting partners (VSIG8 and VSIG3)[33,34], which will greatly benefit the treatment of autoimmune and inflammatory diseases.

In this study, we sought to discover and develop small-molecule antagonists targeting VISTA. Compounds were screened by molecular docking and virtual screening. Then, protein binding activity assays and a cell activity evaluation were performed to provide insights into the development of smallmolecule antagonists of VISTA.

\section{Methods}

\section{Homology modeling of the VISTA 3D structure}

The human VISTA protein extracellular domain without the signal peptide (162 amino acids, UniProt: Q9H7M9) and the murine VISTA protein extracellular domain without the signal peptide (159 amino 
acids, UniProt: Q9D659) were submitted to the I-TASSER online server[35-37] for 3D structure homology modeling.

\section{Virtual screening for VISTA small-molecule hit ligands}

The 3D models of the human/murine VISTA protein extracellular domains as well as their ligand-binding pockets were predicted by $\mathrm{COACH}$. Approximately 130,000 SDF files of structurally diverse small

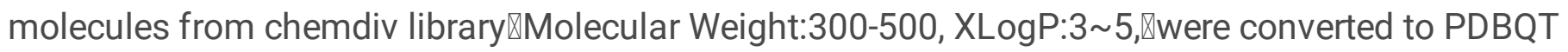
format as ligands using Open Babel (version 2.4)[38-39].The grid (ligand docking search space) was maximized based on the VISTA protein extracellular domain. Then, AutodockVina 1.1.2 was used for the subsequent molecular docking.

Docked ligands located in the predicted ligand-binding pockets with a binding energy lower than -6.0 $\mathrm{kcal} / \mathrm{mol}$ were considered the candidate murine VISTA ligands. The best 20 candidate ligands were selected for the subsequent experimental protein-ligand interaction verification (ELISA)(Suppl. Table 1). The hit ligand verified by the above virtual screening with the lowest Kd values (ELISA) was applied for the VISTA-targeted in vitro experiment.

\section{Visualization of docked ligands with the VISTA protein}

Protein-ligand interactions were visualized using Pymol version 1.7.4.5. The amino acid residues of the human/murine VISTA proteins close to the hit ligands $(\leq 1 \AA)$ were highlighted as potential interactive residues involved in the protein-ligand interaction.

\section{Microscale thermophoresis (MST) experiment}

Murine VISTA-ECD was labeled following the protocol provided in the Monolith $\mathrm{NT}^{\mathrm{TM}}$ Protein Labeling Kit RED-NHS (NanoTemper Technologies $\mathrm{GmbH}$ ). Compound 6809-0223 was prepared in up to 16 serial dilutions and mixed with the labeled protein in the same volume. Then, the mixtures were incubated at room temperature for $30 \mathrm{~min}$ in the dark.

\section{Animals}

Mice (C57BL/6) were purchased from Beijing Vital River Laboratory Animal Technology Co., Ltd. All animal experiments were performed in accordance with the Laboratory Animal Management Committee of Jiangsu Province and approved by the ethics committee of China Pharmaceutical University. To ameliorate any suffering of mice observed throughout these experimental studies, mice were euthanized by $\mathrm{CO} 2$ inhalation.

\section{Murine $\mathrm{CD}^{+}$and $\mathrm{CD} 8^{+} \mathrm{T}$ cell activation assays.}

$\mathrm{CD} 4^{+}$or $\mathrm{CD} 8^{+} \mathrm{T}$ cells were isolated from C57BL/ 6 mice using an EasySep murine $\mathrm{CD} 4^{+}$or $\mathrm{CD} 8^{+} \mathrm{T}$ cell isolation kit (Stem Cell). The cells were cultured in complete RPMI 1640 medium supplemented with 10\% 
FBS, $10 \mathrm{mM}$ Hepes, $50 \mu \mathrm{M}$ 2-mercaptoethanol, 1\% penicillin/streptomycin and 1\% L-glutamine. Purified CD $4^{+}$or $C D 8^{+} T$ cells $(100,000$ cells per well) were cultured in 96 -well flat-bottom plates in the presence of anti-CD3 (clone 2C11) and either VISTA-Ig or control-Ig at the indicated concentration ratios. The cell supernatants were harvested at $48 \mathrm{~h}$ for the cytokine secretion assay. For the proliferation assay, the cells were stained with a 5- (and 6)-carboxyfluorescein diacetate succinimidyl ester (CFSE) kit following the manufacturer's protocol (Biolegend). Cell proliferation was analyzed at $72 \mathrm{~h}$ by CFSE dilution.

\section{Cytometric bead assay (CBA) for $\mathrm{CD}^{+} \mathrm{T}$ cells}

First, 96-well flat-bottom plates were coated with anti-mouse CD3 (clone OKT3, Biolegend) at $2.5 \mu \mathrm{g} / \mathrm{mL}$ together with $5 \mu \mathrm{g} / \mathrm{mL}$ of murine VISTA-ECD protein in PBS at $4^{\circ} \mathrm{C}$ overnight. CD8 ${ }^{+} \mathrm{T}$ cells were plated at a density of $1 \times 10^{5}$ cells/well in complete RPMI medium (RPMI 1640, 10\% heat-inactivated fetal bovine serum, $1 \%$ penicillin-streptomycin, $50 \mu \mathrm{M}$ 2-mercaptoethanol, 10mM HEPEs and 1 mM GlutaMAX ${ }^{\mathrm{TM}}$; all Biological Industries). A titrated amount of compound 6809-0223 was added to the culture medium. The cultured supernatants were collected at $48 \mathrm{~h}$, and the cytokine levels in the supernatant were analyzed using a BD Cytometric Bead Array (CBA) kit according to the manufacturer's instructions.

\section{Statistical analysis}

The data are expressed as the mean \pm SD unless indicated otherwise. An unpaired Student's t-test was used to determine statistically significant differences. A value of $P<0.05$ was considered significant at the $95 \%$ confidence level.

\section{Results}

\section{Virtual screening for VISTA small-molecule hit ligand}

Twenty candidate compounds (binding energy less than $-6 \mathrm{kcal} / \mathrm{mol}$ ) were selected for experimental verification. The predicted binding energie for one hit ligand (6809-0223) showed good binding affinity for murine VISTA. The binding energie for the ligand (6809-0223) was $-9.4 \mathrm{kcal} / \mathrm{mol}$. In the subsequent experiments, we its biological effect on VISTA.

The protein-ligand interaction visualized with the Pymol software was displayed $\otimes$ Fig. $1 \otimes$.The docked position of the ligand (6809-0223) (2 loop areas: 58-62 aa and 150-157 aa) was showed in Fig 1. The overall docked parameter of this protein-ligand interaction was summarized in Table 1.

Table 1 One hit ligand showing significant agonist/antagonist effect 
The murine VISTA protein extracellular domain (159 amino acids, Fig. 2b) is slightly shorter than that of the human VISTA protein (162 amino acids, Fig. 2a). Both VISTA proteins had highly similar structures based on the 3D structural alignment (Fig 2c). The antagonist-interacting residues for the murine VISTA proteins are located in close proximity in the 3D structure(Fig. 2d).

\section{The Kd value of the compound for the VISTA-ECD protein}

The Kd value of compound 6809-0223 for murine VISTA-ECD was measured by MST and calculated as $0.647 \pm 0.0387 \mu \mathrm{M}$ (Fig. 3). Based on the Kd value, the binding affinity of the compounds for mVISTA was relatively weak and was at the micromolar level. The hits identified based on this approach will be a good starting point for further structural optimization in the future.

\section{Murine VISTA antagonist $6809-0223$ increases IL-2 secretion by $\mathrm{CD}^{+}$and $\mathrm{CD} 8^{+} \mathrm{T}$ cells}

Murine T cells were plated in a 96-well plate $\left(1 \times 10^{5}\right.$ cells/well $)$ and then stimulated with a CD3 antibody $(2.5 \mu \mathrm{g} / \mathrm{mL})$ with or without the murine VISTA-Fc protein $(2.5 \mu \mathrm{g} / \mathrm{mL}, 5 \mu \mathrm{g} / \mathrm{mL}$, or $10 \mu \mathrm{g} / \mathrm{mL})$. As the concentration of VISTA increased, the inhibitory effect of murine VISTA-Fc on the secretion of IL-2 by $\mathrm{CD}^{+}$and $\mathrm{CD}^{+}{ }^{+} \mathrm{T}$ cells was enhanced (Fig. $4 \mathrm{a}$ and $4 \mathrm{~b}$ ). Compound $6809-0223$ was added to the cells, and IL-2 was measured by ELISA. The results showed that compound 6809-0223 increased IL-2 secretion by $\mathrm{CD} 4^{+}$and IFN- $\gamma$ secretion by $\mathrm{CD} 8^{+} \mathrm{T}$ cells (Fig. $4 \mathrm{c}$ and $4 \mathrm{~d}$ ).

\section{Compound 6809-0223 increased murine $\mathrm{CD}^{+} \mathrm{T}$ cell proliferation}

$\mathrm{CD} 4^{+} \mathrm{T}$ cell proliferation was analyzed at $72 \mathrm{~h}$ by examining the CFSE profiles. $\mathrm{CD} 4^{+} \mathrm{T}$ cell proliferation was increased after compound 6809-0223 administration (Fig. 5).

\section{Compound 6809-0223 increased cytokine production in CD8 ${ }^{+} \mathrm{T}$ cells based on the CBA assay.}

$\mathrm{CD}^{+} \mathrm{T}$ cells were stimulated with anti-mouse $\mathrm{CD} 3$ antibodies, and mouse VISTA-ECD was added as indicated. The CBA results showed that production of the IL-2, IL-4, IFN- $\gamma$ and TNF-a cytokines was decreased by murine VISTA-Fc. Whereas, IL-2, IL-4, IFN- $\gamma$ and TNF-a production was increased by the addition of compound 6809-0223 (Fig. 6). The results showed that compound 6809-0223 could increase the secretion of certain cytokines, although the mechanism is still under investigation. 


\section{Discussion}

As reported, therapeutic antibodies of immune checkpoints possess high binding affinity for their target protein. However, its low response rate, immune-related toxicities and high cost remain unsolved problems that warrant effort to discover additional immune pathways or find alternatives to antibodybased treatment. As an alternative to monoclonal antibodies, small-molecule modulators are expected to overcome some of the aforementioned disadvantages. Discovery and development of small-molecule drugs for immune checkpoints is a promising and challenging prospect.

We homologously reconstructed the VISTA protein 3D structure using the protein amino acid sequence. Approximately 130,000 chemical compounds from our compound library were virtually screened using the VISTA protein 3D models. After the preliminary screening, potential compounds were tested for VISTA protein binding affinity by ELISA, and the compounds corresponding to the top three test results were selected. These selected compounds were used to adjust the predicted binding position on the VISTA protein for the second round of virtual compound screening, and the candidate molecules were repeatedly subjected to a protein affinity test until the screening results reached a plateau. The final obtained compounds are candidate compounds for verification. Although the amino acid sequence of human VISTA is slightly different from that of murine VISTA, their 3D models are very similar when structurally aligned (RMSD, root mean square deviation $<1 \AA ̊$ ).

The predicted MlogP value of the VISTA binding compound is $2.3 \sim 2.8$. Combined with cellular bioassay, the compound 6809 - 0223 was considered lead compound for VISTA antagonist. ExpiCHO cells were used to express the murine VISTA extracellular domain proteins and obtain high purity murine VISTA proteins by affinity chromatography (suppl. Figure 1). The ELISA screening model was established, and potential compounds from the virtual screen were tested for their murine VISTA protein binding affinity. To the best of our knowledge, this study is the first time to screen and identify VISTA modulators through a eukaryotic expression method. The affinity of the active compound for VISTA was further evaluated using MST experiments. We found that compound $6809-0223$ had high affinity for the murine VISTA protein with $\mathrm{Kd}=0.647 \pm 0.0387 \mu \mathrm{M}$ (Fig. 3). Compound $6809-0223$ increased IL-2 secretion by CD $4^{+}$ and $\mathrm{CD} 8^{+} \mathrm{T}$ cells and increased $\mathrm{CD} 4^{+} \mathrm{T}$ cell proliferation.

In this study, the compound affinity for VISTA was relatively weak, and the activity of the molecule was in the submicromolar range. Therefore, the hit identified based on this approach is a good starting point for future optimization. The crystal structure of VISTA and the compound/VISTA complex are undergoing.

\section{Conclusions}

In summary, affinity active molecule for VISTA was obtained through virtual screening, and the antagonist compound activity to VISTA was assayed in cellular level. We reported a small molecule with high VISTA affinity as antagonist, providing ideas for development VISTA-targeted small molecule compound in cancer immunotherapy. 


\section{Declarations}

\section{Ethics approval and consent to participate}

All animal experiments were performed in accordance with the Laboratory Animal Management Committee of Jiangsu Province and approved by the ethics committee of China Pharmaceutical University.

\section{Consent for publication}

Not applicable.

\section{Availability of data and materials}

All data in the article can be requested from the corresponding author.

\section{Competing interests}

The authors have no conflict of interest to declare.

\section{Funding}

This research was funded by the National Natural Science Foundation of China (No. 81673443 and No.81973361), Double First-Class University Plan (No. CPU2018GY38 and No.CPU2018GY01). The funding body didn't have any role in the design, collection, analysis, and interpretation of data or in the writing of the manuscript.

\section{Author contribution}

$\mathrm{JL}$ designed the research, contributed to the execution of the research, analyzed the data and wrote the manuscript. TTL and CXQ performed the research; JWJ performed the molecular docking and virtual screening, CXX and XLH provided the materials and protocols. WML and WTC performed the experiments and analyzed the data.

\section{Acknowledgments}

Not applicable.

\section{Abbreviations}

Not applicable.

\section{References}


1. Zou, W.; Chen, L. Inhibitory B7-family molecules in the tumour microenvironment. Nat Rev Immunol. 2008;8:467-477. https://doi.org/1038/nri2326.

2. Greenwald, R. J.; Freeman, G. J.; Sharpe, A. H. The B7 family revisited. Annu Rev Immunol. 2005;23:515-548. https://doi.org/10.1146/annurev.immunol.23.021704.115611.

3. Sharma, P.; Allison, J. P. Immune Checkpoint Targeting in Cancer Therapy: Toward Combination Strategies with Curative Potential. 2015;161:205-214. https://doi.org/10.1016/j.cell.2015.03.030.

4. Topalian, S. L.; Drake, C. G.; Pardoll, D. M. Immune Checkpoint Blockade: A Common Denominator Approach to Cancer Therapy. Cancer Cell. 2015;27:450-461. https://doi.org/10.1016/j.ccell.2015.03.001.

5. Shin, D. S.; Ribas, A. The Evolution of Checkpoint Blockade as a Cancer Therapy: What's Here, What's Next? Curr Opin Immunol. 2015;33:23-35. https://doi.org/10.1016/j.coi.2015.01.006.

6. Hoos, A. Development of Immuno-Oncology Drugs-from CTLA4 to PD1 to the next Generations. Nat Rev Drug Discov. 2016;15:235-247. https://doi.org/10.1038/nrd.2015.35.

7. Khalil, D. N.; Smith, E. L.; Brentjens, R. J.; Wolchok, J. D. The Future of Cancer Treatment: Immunomodulation, CARs and Combination Immunotherapy. Nat Rev Clin Oncol. 2016;13:273-290. https://doi.org/10.1038/nrclinonc.2016.65.

8. Mahoney, K. M.; Rennert, P. D.; Freeman, G. J. Combination Cancer Immunotherapy and New Immunomodulatory Targets. Nat Rev Drug Discov. 2015;14:561-584. https://doi.org/10.1038/nrd4591.

9. Wang L.; Rubinstein R.; Lines J.L.; Wasiuk A.; Ahonen C.; Guo Y.; Lu L.F.; Gondek D; Wang Y.; Fava R.A.; Fiser A.; Almo S.; Noelle R.J. VISTA, a novel murine Ig superfamily ligand that negatively regulates T cell responses. J Exp Med. 2011;208:577-592. https://doi.org/10.1084/jem.20100619.

10. Gavrieli M.; Sedy J.; Nelson C.A.; Murphy K.M. BTLA and HVEM cross talkregulates inhibition and costimulation. Adv Immunol. 2006;92:157-185. https://doi.org/10.1016/S0065-2776(06)92004-5.

11. Yi K.H.; Chen L. Fine tuning the immune response through B7-H3 and B7-H4. Immunol Rev. 2009;229:145-151. https://doi.org/10.1111/j.1600-065X.2009.00768.x.

12. Anderson A.C.; Joller N.; Kuchroo V.K. Lag-3, Tim-3, and TIGIT: Co-inhibitory Receptors with Specialized Functions in Immune Regulation. 2016;44:989-1004. https://doi.org/10.1016/j.immuni.2016.05.001.

13. Andrews L.P.; Marciscano A.E.; Drake C.G.; Vignali D.A. LAG3 (CD223) as a cancer immunotherapy target. Immunol Rev. 2017;276:80-96. https://doi.org/10.1111/imr.12519.

14. Lines J.L.; Sempere L.F.; Broughton T.; Wang L.; Noelle R. VISTA is a novel broad-spectrum negative checkpoint regulator for cancer immunotherapy. Cancer Immunol Res. 2014;2:510-517. https://doi.org/10.1158/2326-6066.CIR-14-0072.

15. Janakiram M.; Shah U.A.; Liu W.; Zhao A.; Schoenberg M.P.; Zang X. The third group of the B7-CD28 immune checkpoint family: HHLA2, TMIGD2, B7x, and B7-H3. Immunol Rev. 2017;276:26-39. https://doi.org/10.1111/imr.12521. 
16. Mehta Nishant.; Maddineni Sainiteesh.; Mathews Irimpan I et al. Structure and Functional Binding Epitope of V-domain Ig Suppressor of T Cell Activation. Cell Rep. 2019;28:2509-2516.e5. https://doi.org/10.1016/j.celrep.2019.07.073.

17. Johnston Robert J.; Su Linhui Julie.; Pinckney Jason et al. VISTA is an acidic pH-selective ligand for PSGL-1. Nature. 2019;574: 565-570. https://doi.org/10.1038/s41586-019-1674-5.

18. Zielinski C.; Knapp S.; Mascaux C.; Hirsch F. Rationale for targeting the immune system through checkpoint molecule blockade in the treatment of non-small-cell lung cancer. Ann Oncol. 2013;24(5): 1170-1179. https://doi.org/10.1093/annonc/mds647.

19. Böger C.; Behrens H.M.; Krüger S.; Röcken C. The novel negative checkpoint regulator VISTA is expressed in gastric carcinoma and associated with PD-L1/PD-1: A future perspective for a combined gastric cancer therapy? 2017;6(4): e1293215 Feb 21.

https://doi.org/10.1080/2162402X.2017.1293215.

20. Wu L.; Deng W.W.; Huang C.F.; Bu L.L.; Yu G.T.; Mao L.; Zhang W.F.; Liu B.; Sun Z.J. Expression of VISTA correlated with immunosuppression and synergized with CD8 to predict survival in human oral squamous cell carcinoma. Cancer Immunol Immunother. 2017;66(5):627-636. https://doi.org/10.1007/s00262-017-1968-0.

21. Gao J.; Ward J.F.; Pettaway C.A.; Shi L.Z.; Subudhi S.K.; Vence L.M.; Zhao H.; Chen J.; Chen H.; Efstathiou E.; Troncoso P.; Allison J.P.; Logothetis C.J.; Wistuba I.I.; Sepulveda M.A.; Sun J.; Wargo J.; Blando J.; Sharma P. VISTA is an inhibitory immune checkpoint that is increased after ipilimumab therapy in patients with prostate cancer. Nat Med. 2017;23:551-555. https://doi.org/10.1038/nm.4308.

22. Villarroel-Espindola F.; Yu X.; Datar I.; Mani N.; Sanmamed M.; Velcheti V, Syrigos K.; Toki M.; Zhao H.; Chen L.; Herbst R.S.; Schalper K.A. Spatially Resolved and Quantitative Analysis of VISTA/PD-1H as a Novel Immunotherapy Target in Human Non-Small Cell Lung Cancer. Clin Cancer Res. 2018;24:15621573. https://doi.org/10.1158/1078-0432.CCR-17-2542.

23. Kakavand H.; Jackett L.A.; Menzies A.M.; Gide T.N.; CarlinoM.S.; Saw RPM.; , Thompson J.F.; Wilmott J.S.; Long G.V.; Scolyer R.A. Negative immune checkpoint regulation by VISTA: a mechanism of acquired resistance to anti-PD-1 therapy in metastatic melanoma patients. Mod Pathol. 2017;30:1666-1676. https://doi.org/10.1038/modpathol.2017.89

24. Liu J.; Xie X.; Xuan C.; Li T.; Wang L.; Teng L.; Liu J. High-Density Infiltration of V-domain Immunoglobulin Suppressor of T-cell Activation Up-regulated Immune Cells in Human Pancreatic Cancer. Pancreas. 2018;47(6):725-731. https://doi.org/ 10.1097/MPA.0000000000001059.

25. A study of safety, pharmacokinetics, pharmacodynamics of JNJ-61610588 in participants with advanced cancer. https://clinicaltrials.gov/. Cited 6 May 2018.

26. Spaller M.; Noelle R.; Ceeraz S.; Lemercier I.; Nowak E.; Lines J.et al. VISTA antagonist and methods of use[P].US: WO2015109340.2015-07-23.

27. Sasikumar PGN, Ramachandra M, Naremaddepalli SSS. VISTA signaling pathway inhibitory compounds useful as immunomodulators[P]. IN: WO2018047143, 2018-03-15. 
28. Sasikumar P.G.; Naremaddepalli S.S.; Ramachandra R.K.; Gowda N.; Yerramsetti M.R.; Bandireddy S.R.; Adurthi S.; Mani J.; Nair R.; Dhudashia A.A.; Dodheri S.S.; Gowda N.M.; Ramachandr M. Functional antagonism of VSIG8-mediated immune suppression by oral VISTA agents. Mol Cancer Ther. 2018;17:B006. https://doi.org/10.1158/1535-7163.

29. A study of CA-170 (Oral PD-L1, PD-L2 and VISTA checkpointantagonist) in patients with advanced tumors and lymphomas. https://clinicaltrials.gov/ Cited 19 Jun 2018.

30. Sasikumar, P. G.; Ramachandra, M. Small-Molecule Immune Checkpoint Inhibitors Targeting PD1/PD-L1 and Other Emerging Checkpoint Pathways. BioDrugs. 2018;32(5):481https://doi.org/10.1007/s40259-018-0303-4.

31. Wang, T.; Wu, X.; Guo, C.; Zhang, K.; Xu, J.; Li, Z.; Jiang, S. Development of Inhibitors of the Programmed Cell Death-1/Programmed Cell Death-Ligand 1 Signaling Pathway. J Med Chem. 2019;28:1715-1730. https://doi.org/10.1021/acs.jmedchem.8b00990.

32. Blevins Derek J.; Hanley Ronan.; Bolduc Trevor et al. In Vitro Assessment of Putative PD-1/PD-L1 Inhibitors: Suggestions of an Alternative Mode of Action. ACS Med Chem Lett. 2019;10:1187-1192. https://doi.org/10.1021/acsmedchemlett.9b00221.

33. Yang W.; Padkjær S.B.; Wang J.; Sun Z.; Shan B.; Yang L.; Chen H.; Kang L.; Madsen D.; Li X.; Shen C.; Yu B.; Zhu H.; Chao T.Y.; Cao Z.; Li D.; Liu W.; Du Y.; Xu J.; Hao D.; Xu F.; Peng L.; Li T.; Wang L.; Li L.; Xing H.; Liu D.; Liu Z.; Guan Z.;Wang W.; Cheng H.; Østergaard H.; Chang C.; Yang Z.; Boel E.; Su J. Construction of a versatile expression library for all human single-pass transmembrane proteins for receptor pairings by high throughput screening. J Biotechnol. 2017;260:18-30. https://doi.org/10.1016/j.jbiotec.2017.08.023.

34. Prodeus A.; Abdul-Wahid A.; Sparkes A.; Fischer N.W.; Cydzik M.; Chiang N.; Alwash M.; Ferzoco A.; Vacaresse N.; Julius M.; Gorczysnki R.M.; Gariépy J. VISTA.COMP-an engineered checkpoint receptor agonist that potently suppresses T cell-mediated immune responses. JCI Insight. 2017;2:94308. https://doi.org/10.1172/jci.insight.94308

35. J Yang, R Yan, A Roy, D Xu, J Poisson, Y Zhang. The I-TASSER Suite: Protein structure and function prediction. Nature Methods. 2015;12:7-8. https://doi.org/10.1038/nmeth.3213.

36. A Roy, A Kucukural, Y Zhang. I-TASSER: a unified platform for automated protein structure and function prediction. Nature Protocols. 2010;5:725-738. https://doi.org/10.1038/nprot.2010.5.

37. Y Zhang. I-TASSER server for protein 3D structure prediction. BMC Bioinformatics vol. 2008;9:40. https://doi.org/1186/1471-2105-9-40.

38. Jianyi Yang, Ambrish Roy, and Yang Zhang. Protein-ligand binding site recognition using complementary binding-specific substructure comparison and sequence profile alignment. Bioinformatics. 2013;29: 2588-2595. https://doi.org/10.1093/bioinformatics/btt447.

39. Jianyi Yang, Ambrish Roy, and Yang Zhang. BioLiP: a semi-manually curated database for biologically relevant ligand-protein interactions. Nucleic Acids Research. 2013;41:D1096-D1103. https://doi.org/10.1093/nar/gks966. 


\section{Figures}

a

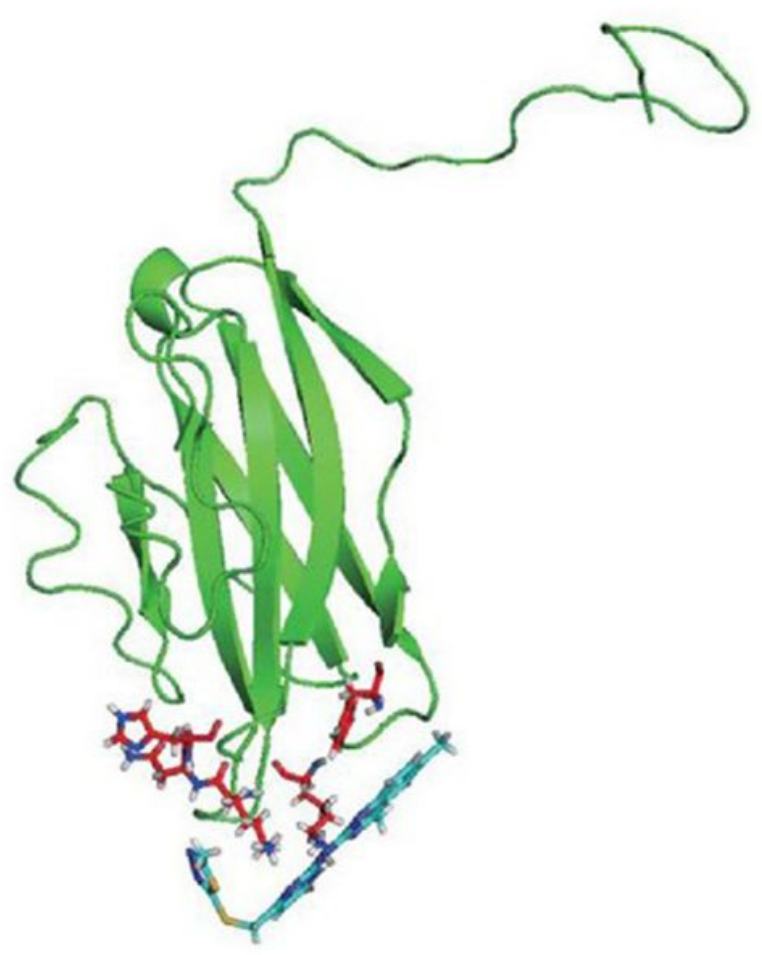

b<smiles>Cc1ccc2nc(Nc3nc(CSc4nnc(C)s4)cc(=O)[nH]3)nc(C)c2c1</smiles>

\section{Figure 1}

(a) Antagonist ligands (light blue) interacting with local residues of the murine VISTA protein (green). Residues on the VISTA protein interacting with antagonist ligands are highlighted in red. Figure 1a shows the whole VISTA protein extracellular domain and the docked positions of the ligand (6809-0223). (b) Structure of compound 6809-0223. 
a

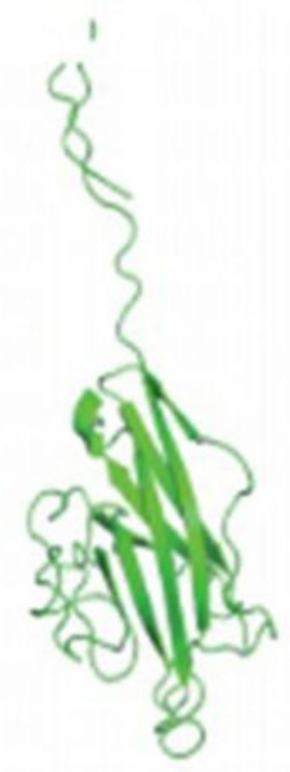

C

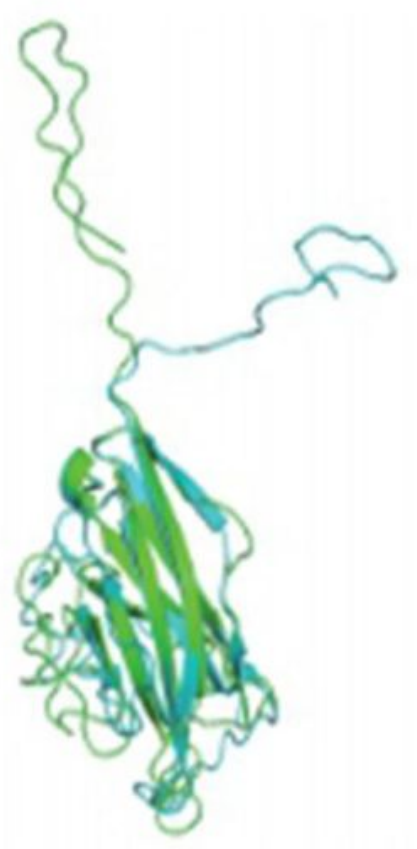

b
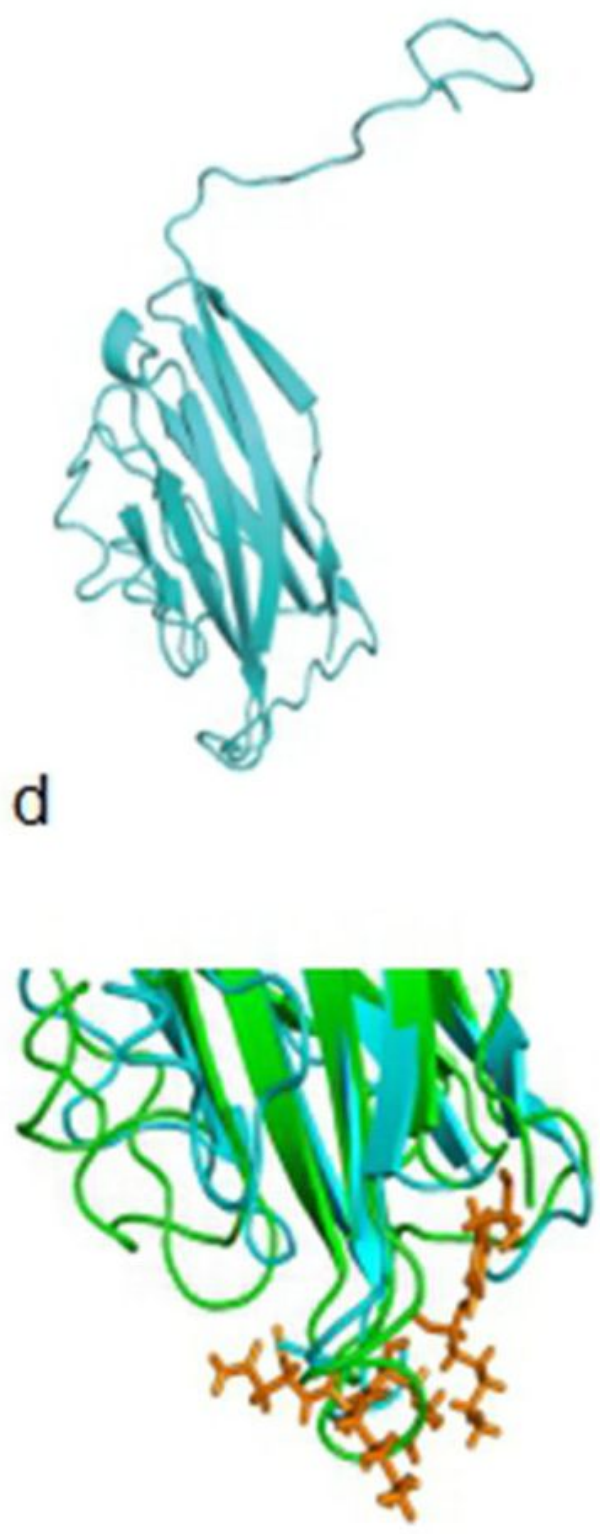

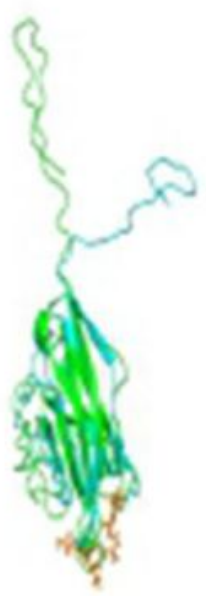

\section{Figure 2}

The 3D structural comparison between the human and murine VISTA proteins and their ligand-interacting residues. (a) The human VISTA protein extracellular domain (green); (b) The murine VISTA protein extracellular domain (light blue); (c) Aligned human VISTA protein (green) and murine VISTA protein (light blue); (d) Ligand interacting residues: murine VISTA antagonist interacting residues (orange), 3D structural alignment of the whole human/murine VISTA protein extracellular domain (bottom right). 


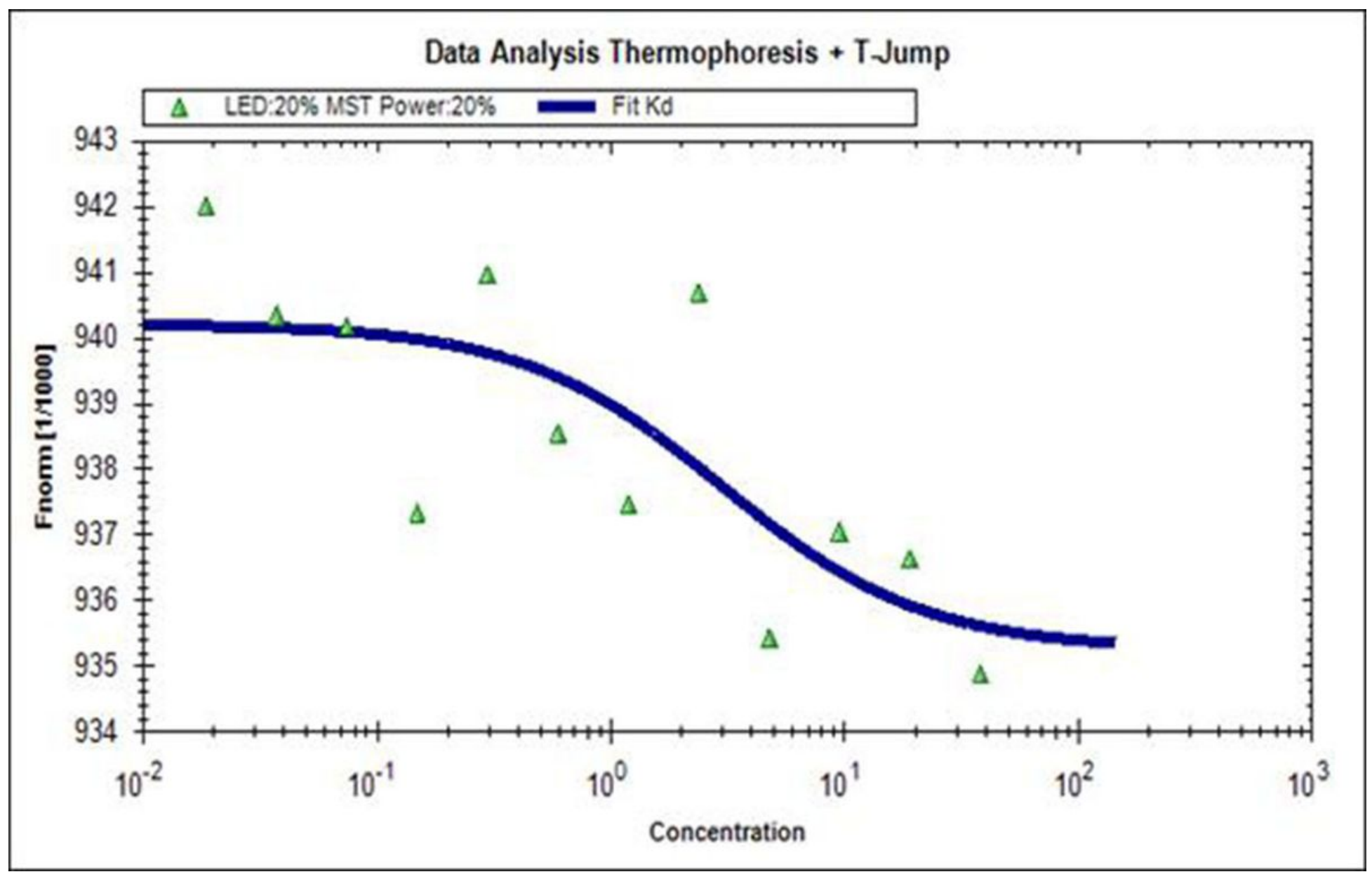

Figure 3

Binding affinity was evaluated between the murine VISTA-ECD protein and compound $6809-0223$ by the MST experiment. All results were repeated three times with consistent results. 


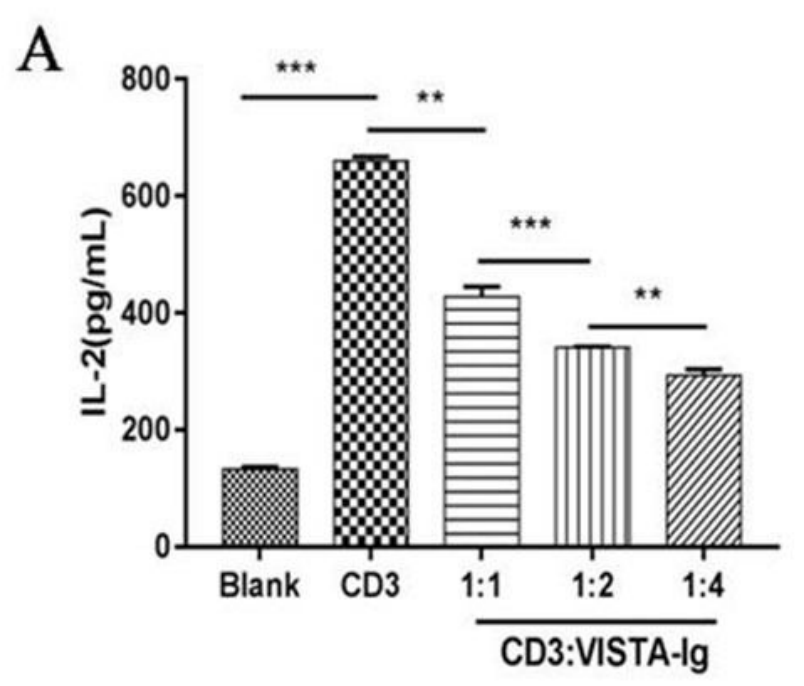

B
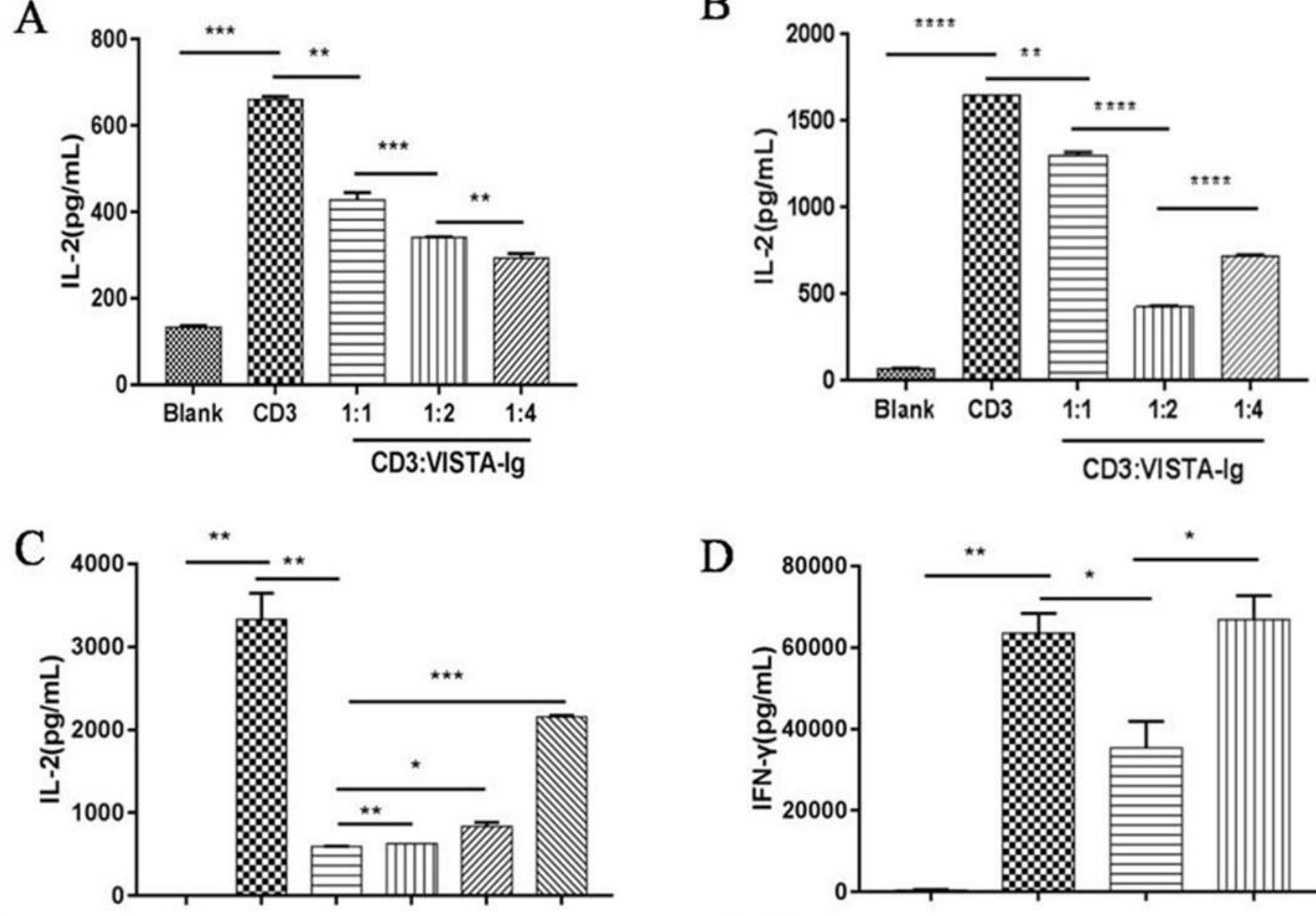

CD3 $(2.5 \mu \mathrm{g} / \mathrm{mL})$

VISTA $(10 \mu \mathrm{g} / \mathrm{mL})$

6809-0223
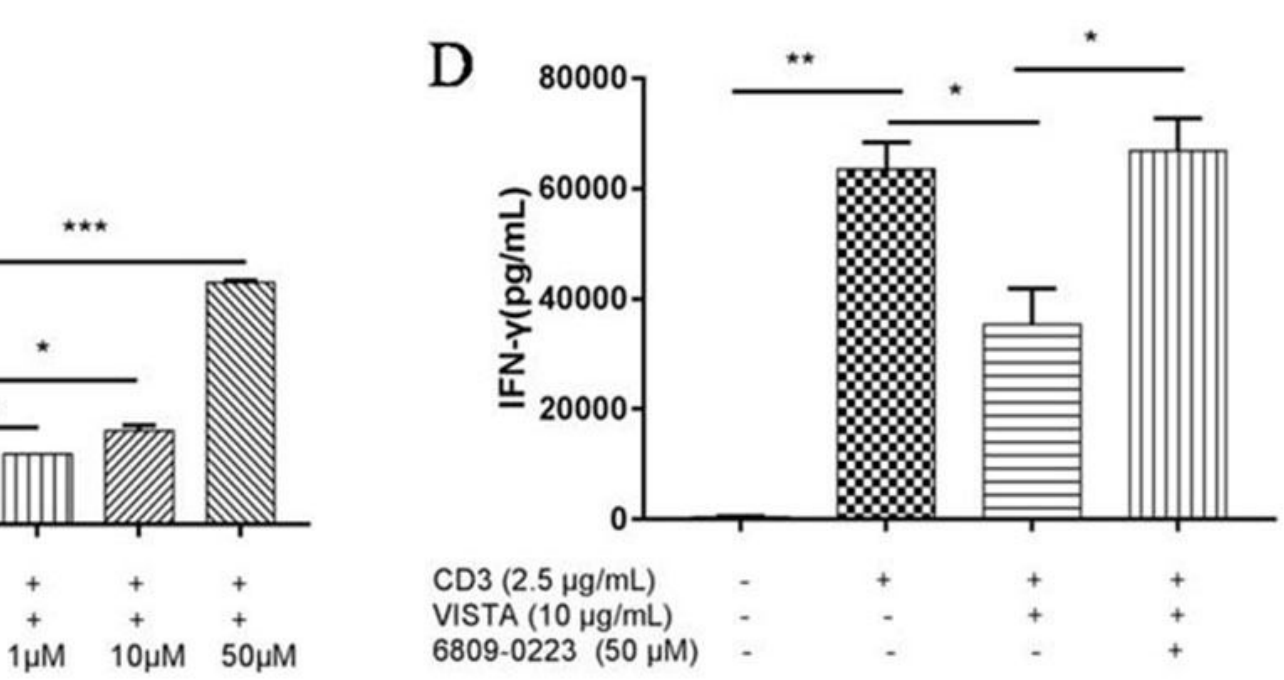

Figure 4

The murine VISTA protein inhibited cytokine production in T cells. (a) CD4+ T cells ( $1 \times 105$ cells/well) were stimulated with anti-CD3 (2C11) at $2.5 \mu \mathrm{g} / \mathrm{mL}$ and murine VISTA at ratios of 1:1, 1:2, and 1:4. Culture supernatants were collected at 48 hours. IL-2 production was analyzed by ELISA. (b) CD8+ T cells ( $1 \times 105$ cells/well) were stimulated with anti-CD3 (2C11) at $2.5 \mu \mathrm{g} / \mathrm{mL}$ and murine VISTA at ratios of 1:1, $1: 2$, and 1:4. Culture supernatants were collected at 48 hours. IL-2 production was analyzed by ELISA. (c) Purified CD 4+ T cells $(1 \times 105$ cells/well) were stimulated with anti-CD3 $(2.5 \mu \mathrm{g} / \mathrm{mL})$ and the murine VISTA protein as indicated. Culture supernatants were collected after $48 \mathrm{~h}$. IL-2 production was analyzed by ELISA. (d) Bulk purified CD $8+T$ cells $(1 \times 105$ cells/well) were stimulated with anti-CD3 $(2.5 \mu \mathrm{g} / \mathrm{mL})$ and the murine VISTA protein $(5 \mu \mathrm{g} / \mathrm{mL})$. Culture supernatants were collected at 48 hours. IFN-y production was analyzed by ELISA. ${ }^{*} P<0.05,{ }^{*} P<0.01,{ }^{*} * * P<0.001,{ }^{\star} * \star \star * P<0.0001$. All results were repeated three times with consistent results $(\mathrm{n}=3)$. 

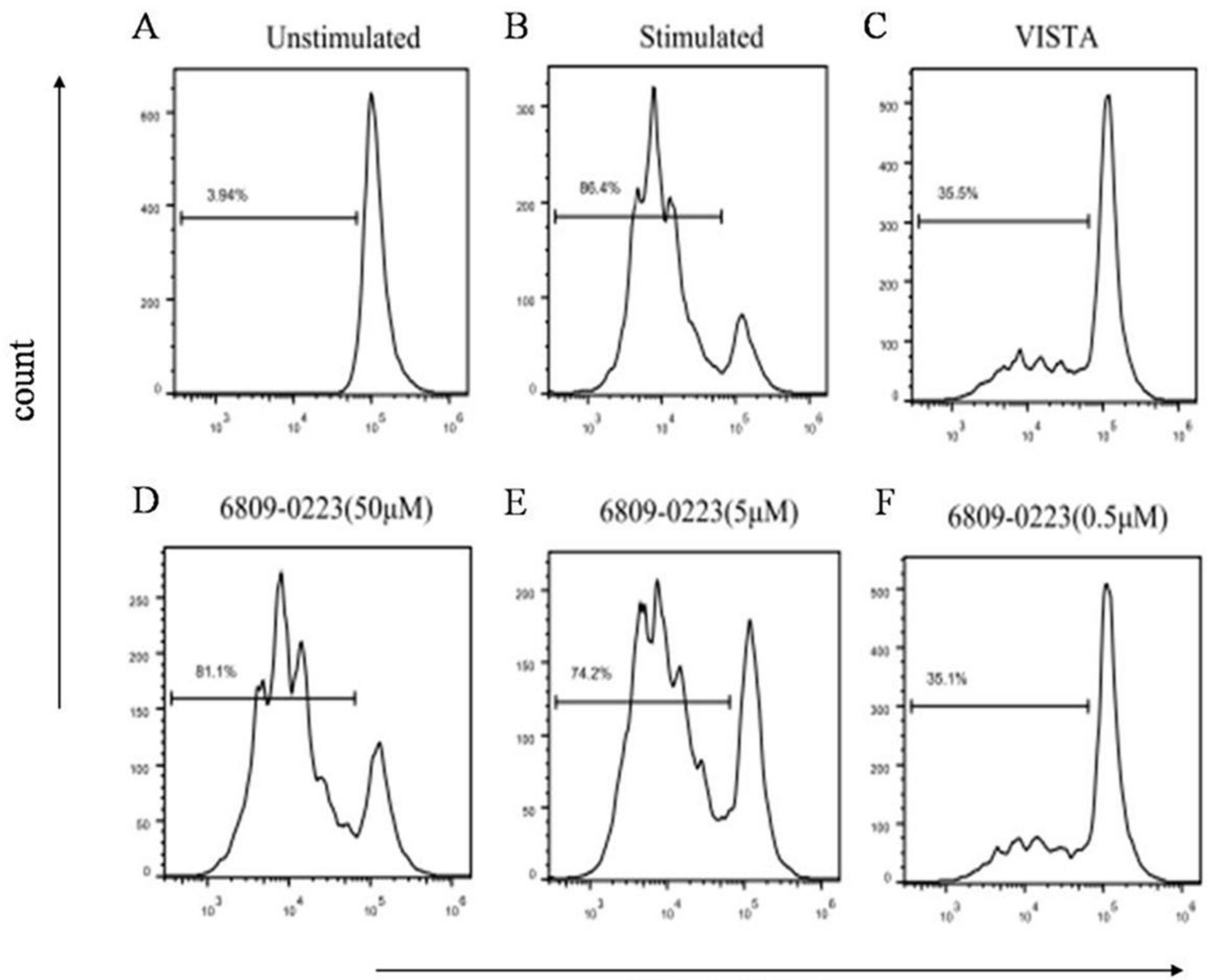

FL1-A:CFSE

Figure 5

Compound 6809-0223 increases CD4+ T cell proliferation. CFSE-labeled cells were stimulated with antiCD3 (2C11) at $2.5 \mu \mathrm{g} / \mathrm{mL}$ and murine VISTA-Fc at $5 \mu \mathrm{g} / \mathrm{mL}$. Each well was seeded with $1 \times 105$ cells/well. Cell supernatants were collected for flow cytometry at 72 hours. Compound 6809-0223 promoted CD4+ T cell proliferation. All results were repeated three times with consistent results( $n=3)$. 


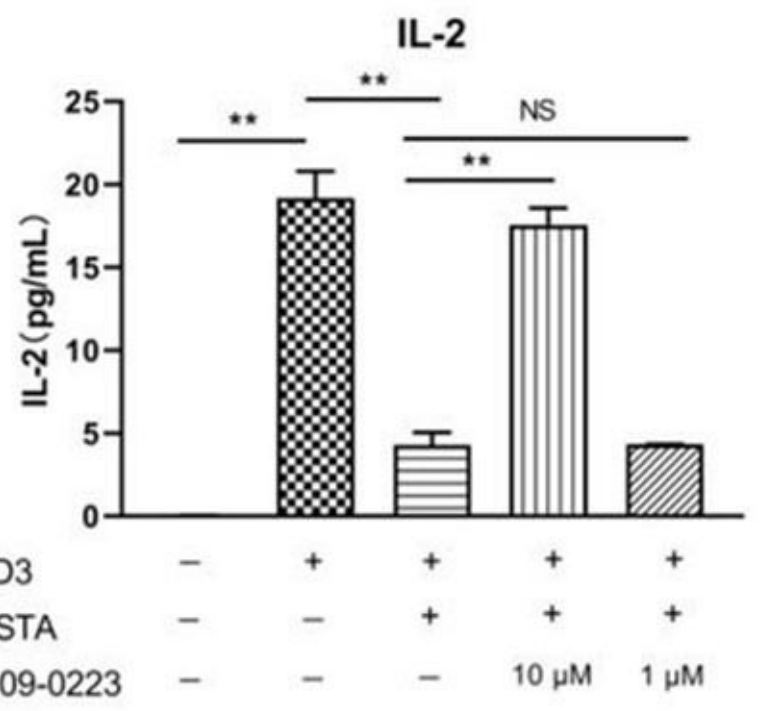

IFN-Y

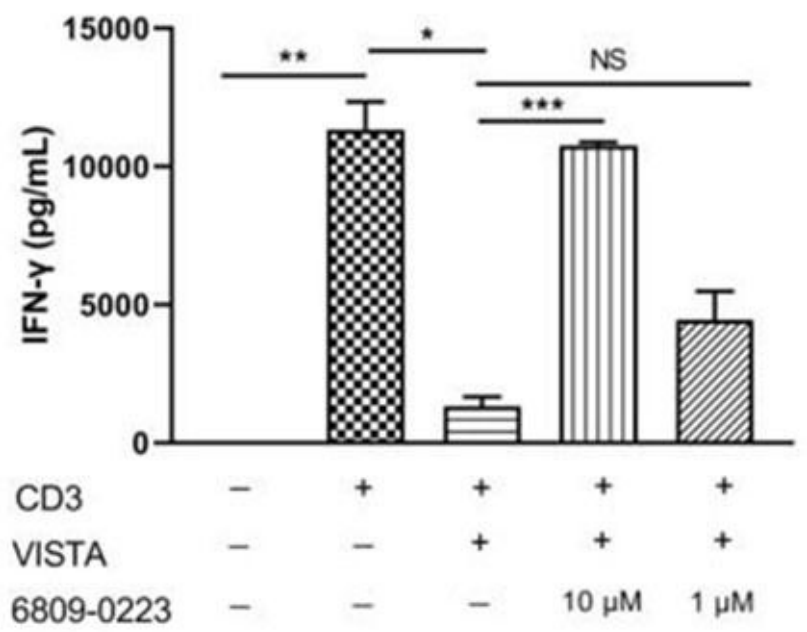

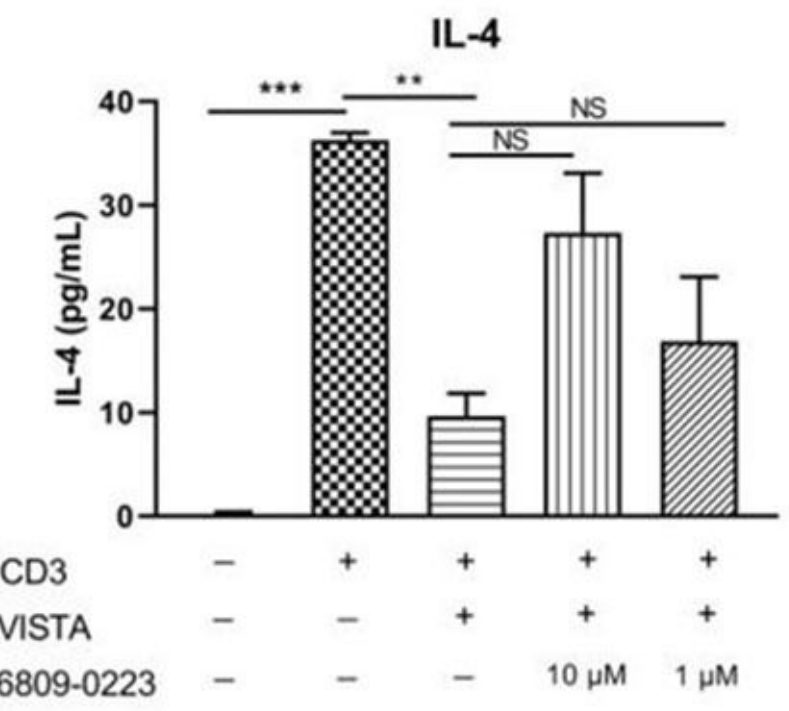

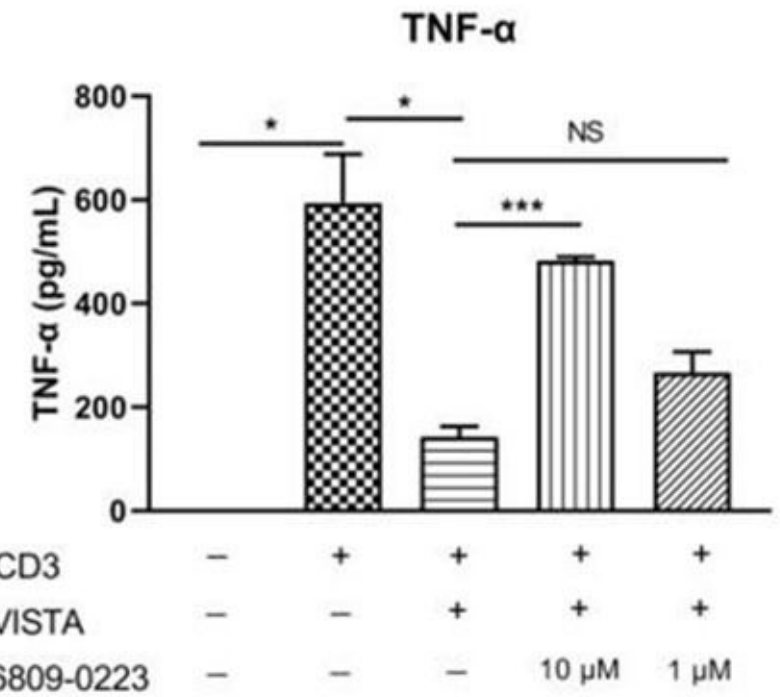

\section{Figure 6}

The activity of compound 6809-0223 was detected by CBA in CD8+ T cells. Cells (11105 cells/well) were incubated with an immobilized anti-mouse CD3 antibody $(2.5 \mu \mathrm{g} / \mathrm{mL})$ and mouse VISTA-ECD at $5 \mu \mathrm{g} / \mathrm{mL}$, and compound 6809-0223 was added as indicated. The levels of (a) IL-2, (b) IL-4, (c) IFN- $y$, (d) TNF-a in the cell culture supernatants were measured at $48 \mathrm{~h}$ with Cytometric Bead Array (CBA) Kits $(n=3)$.

\section{Supplementary Files}

This is a list of supplementary files associated with this preprint. Click to download.

- SupplementalResults.doc

- NC3RsARRIVEGuidelinesChecklist2014.docx 